\title{
Review Article \\ Prognosis and Outcome Predictors in Psychogenic Nonepileptic Seizures
}

\author{
Joseph Durrant, ${ }^{1}$ Hugh Rickards, ${ }^{1}$ and Andrea E. Cavanna ${ }^{1,2}$ \\ ${ }^{1}$ Department of Neuropsychiatry, BSMHFT and University of Birmingham, Barberry Building, 25 Vincent Drive, \\ Birmingham B152FG, UK \\ ${ }^{2}$ Department of Neuropsychiatry, UCL Institute of Neurology, London WC1N 3BG, UK
}

Correspondence should be addressed to Andrea E. Cavanna, a.cavanna@ion.ucl.ac.uk

Received 27 October 2010; Accepted 11 January 2011

Academic Editor: Luigi Maria Specchio

Copyright (C) 2011 Joseph Durrant et al. This is an open access article distributed under the Creative Commons Attribution License, which permits unrestricted use, distribution, and reproduction in any medium, provided the original work is properly cited.

It is estimated that one in five patients referred to specialist epilepsy clinics for refractory seizures have psychogenic nonepileptic seizures (PNES). Despite the high prevalence, little is known about the prognosis of patients with PNES. In this paper we set out to systematically assess published original studies on the prognosis and outcome predictors of patients with PNES. Our literature search across the databases Medline, PsycINFO, and EMBASE generated 18 original studies meeting the search criteria. Prognosis was found to be poor in adults, but good in children. Predictors of poor outcome included the presence of coexisting epilepsy or psychiatric comorbidities, violent seizure phenomenology, dependent lifestyle, and poor relationships. Overall, too much reliance is placed on seizure remission as an outcome measurement for patients with PNES, and the impact of many of the outcome predictors requires evaluation using larger studies with longer followup.

\section{Introduction}

Psychogenic nonepileptic seizures (PNESs) are paroxysmal changes in behavior resembling epileptic seizures, in the absence of electrophysiological brain correlates. Timelimited changes in behavioral, motor, sensory, cognitive, and emotional function are all common features, with observers and clinicians often mistaking the condition for epilepsy. PNESs are often considered to be physical manifestations of underlying psychological stressors, despite being perceived as involuntary $[1,2]$.

PNESs have an incidence of $1.4 / 100,000$ people per year [3], but it is estimated that about $20 \%$ of the patients referred to tertiary care epilepsy centers for refractory seizures have this condition [4], making it an important issue in this context. Patients with PNES are often misdiagnosed with epilepsy and treated with antiepileptic drugs (AEDs) for a number of years, resulting in unnecessary exposure to AEDs' side effects. Patients with PNES can also be offered invasive procedures on the assumption that their seizures are manifestations of an underlying treatment-refractory epileptic disorder [5]. Because of these problems, clinical research on patients with PNES has mainly focussed on the differential diagnosis with epilepsy, somewhat neglecting the question of long-term outcome, which is essential for the optimization of therapeutic resources for this patient population.

This paper is aimed at systematically assessing the scientific literature on the prognosis of PNES, in order to identify the most reliable outcome predictors.

\section{Methods}

A systematic literature search was conducted on the databases PsycINFO, EMBASE, and Medline. In consideration of the wide variation in terminology currently in use to describe PNES, we employed a broad range of search terms: "pseudoseizures"; "nonepileptic attack disorder"; "nonepileptic seizures"; "psychogenic seizures"; "nonepileptic paroxysmal disorder"; "psychogenic nonepileptic seizures"; "pseudoepileptic attack disorder"; "psychogenic pseudoseizures"; "dissociative 
episodes", and "hysterical seizures", with "seizures" replaced by "attacks" and "fits" in each search. Titles and abstracts were reviewed for relevance and full texts were then retrieved and further assessed for inclusion; both prospective and retrospective studies were included in the review. We limited our search to papers published in English language after 1980, and nonoriginal studies and case reports were excluded.

\section{Results}

3.1. Prognosis. The results of the literature search are summarized in Table 1. A total of 18 studies were identified as relevant from an initial search result of 368. Overall, prognosis of PNES appears to be poor. Ten out of the 18 studies which met our search criteria found that $40 \%$ or less patients with PNES achieve seizure remission in the followup period. Of the studies with over $50 \%$ seizure remission, three contained paediatric cases only [5-7] and one had a relatively short followup period of two weeks [8]. Riaz and colleagues found that the majority of patients with PNES (67\%) had a good outcome [9], but this was defined as either seizure cessation or greater-than-50\% reduction in seizure frequency.

The largest study $(n=260)$ [10] found that just 38\% of patients were seizure-free 6-12 months after diagnosis. However 19\% actually had an increase in the frequency of seizures, showing that for a minority of patients, the condition worsens. Outcomes were recorded during two followup periods, 6 months and 12 months after diagnosis. Only $40 \%$ of the patients attended both followups, with improving seizure frequency over time: $21 \%$ of patients had seizure remission at 6 months, increasing to $33 \%$ at 12 months. There was also a significant reduction in the number of patients presenting to the emergency department 6 months after diagnosis. This is a significant outcome measure, as patients with PNES are at risk of adverse reactions from emergency treatment, including artificial ventilation [5]. The final outcome measured showed that employment increased at follow up from $10 \%$ to $23 \%$. These results indicate that although the overall prognosis is poor, seizures can improve with time.

In one of the studies with the longest followup, Reuber et al. [11] found that $71 \%$ of patients were still having seizures 1-10 years after diagnosis. In addition, just $41 \%$ were in employment or at school, with the remainder being unemployed $(12 \%)$, retired on health grounds $(41 \%)$ or receiving a pension $(5 \%)$.

While complete cessation appears to be an ambitious target for many patients with PNES, reduction of seizures is a common outcome across the reviewed studies. Carton et al. [12] found that although only $28 \%$ of patients followed up at $1-7$ years were seizure free, $48 \%$ had at least a $50 \%$ reduction in the frequency of seizures following diagnosis. Bodde et al. [13] found a similar pattern, with only $32 \%$ of patients having complete seizure remission, but also reported a significant fall in the number of patients experiencing daily seizures from 9 (out of 22) to 2. The majority of studies found that patients had an overall fall in the number of seizures while only a minority managed to fully eradicate their attacks.

Overall, the studies conducted in pediatric populations found a better prognosis. Bhatia and Sapra [6], Irwin et al. [7], and Wyllie et al. [5] found seizure remission at follow up to be $72 \%, 66 \%$, and $78 \%$, respectively. Although these studies were limited by the relatively small sample sizes, their conclusions agree that the prognosis in children is far better than adults. Wyllie et al. [5] found that $57 \%$ of the sample had no seizures after diagnosis, $22 \%$ had ongoing seizures, whilst, interestingly, $43 \%$ had gradually reducing seizure frequency over a period of 3 to 48 months, highlighting the need for longer followup periods in studies of PNES outcome.

3.2. Predictive Factors. A wide variety of patient characteristics have been implicated in predicting outcome of PNES (Table 2). In the present review we discussed these findings by domain groups.

3.2.1. Age. Age at onset clearly affects prognosis. Studies on pediatric populations show a higher rate of seizure remission than in adults. The effect of increasing age in those above 18 is less clear. An et al. [14] showed that the risk of still having seizures after a mean followup of 16 months increased by almost 3 times for every 10-year increase in age at onset. This would suggest an effect of age on prognosis independent of the better prognosis in children, except that minors were included in this study explaining some of the effect. Reuber et al. [11] found no significant effect of varying age in adults at onset on prognosis, but they did find that increased age at diagnosis resulted in a poorer outcome.

3.2.2. Gender. Female gender was predominant in the majority of the studies reviewed. However the findings on the influence of gender on prognosis are inconsistent. Only two studies found that gender significantly affected outcome, despite almost every study recording the gender of the patients and analysing its influence. McKenzie et al. [10] found that male gender significant predictor of seizure remission at followup $(\mathrm{OR}=2.46$; CI $1.18-5.20)$ in 260 patients. However, Meierkord et al. [15] found female patients to have a better prognosis in a sample of 70. Clearly, the evidence is equivocal and needs further investigation.

3.2.3. Socioeconomic Factors. Different studies implicated that socioeconomic factors can affect outcome of PNES. In the study by McKenzie et al. [10], patients not receiving social security payments were 2.3 times more likely $(\mathrm{OR}=0.43$; $P=.014$ ) to become seizure-free. In a smaller study of 84 patients by Carton et al. [12], seizure remission at 1 to 7 years followup was more likely to be reported in those who were employed at diagnosis.

The ability to form relationships and maintain independence can result in improved outcomes of PNES. There is evidence that patients who are independent have a much better prognosis, with two studies agreeing that these patients are more likely to be seizure-free $[15,16]$. Having many 


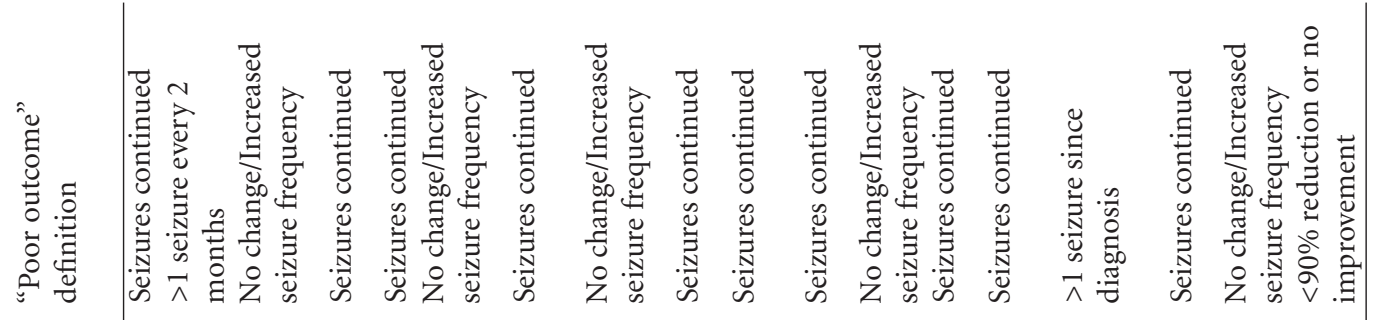

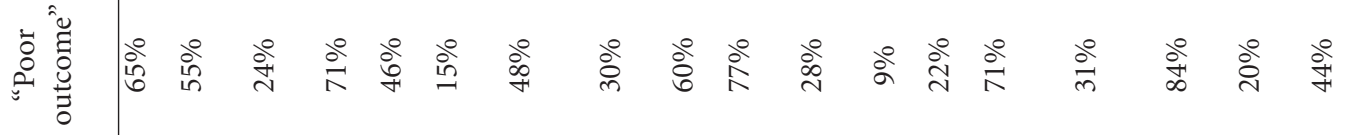

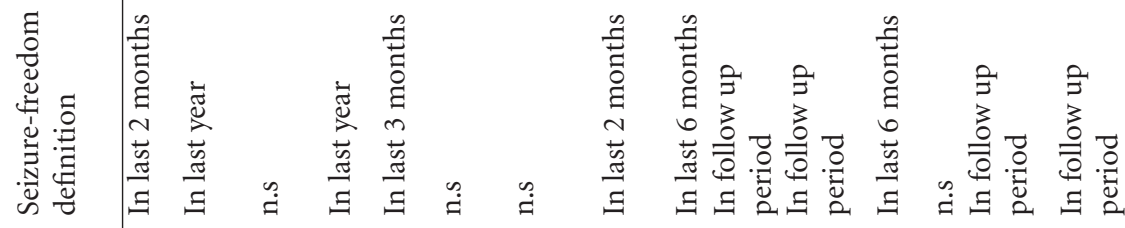

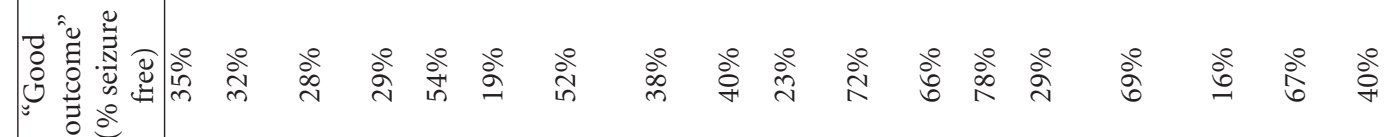

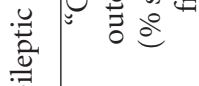

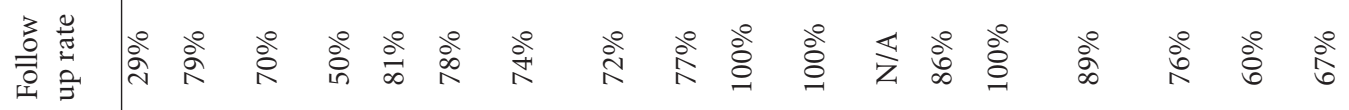

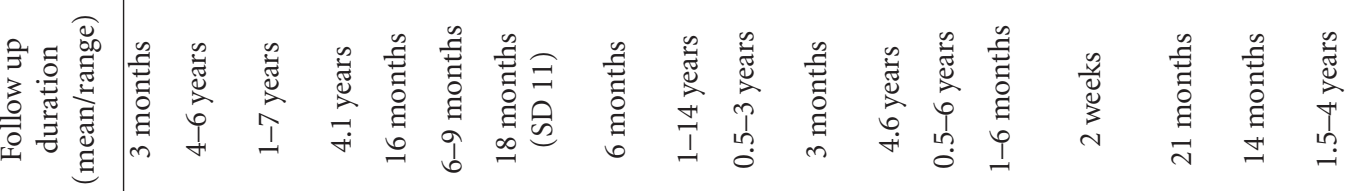

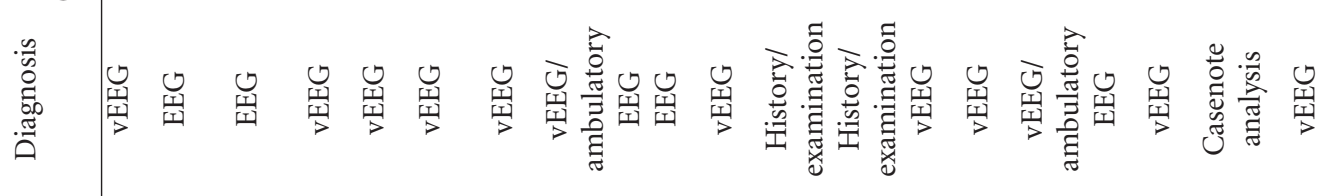

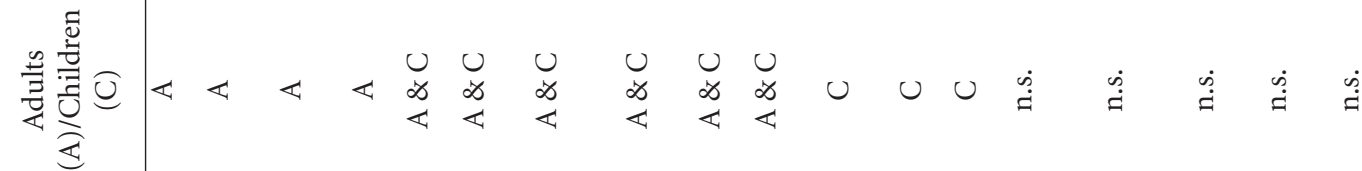

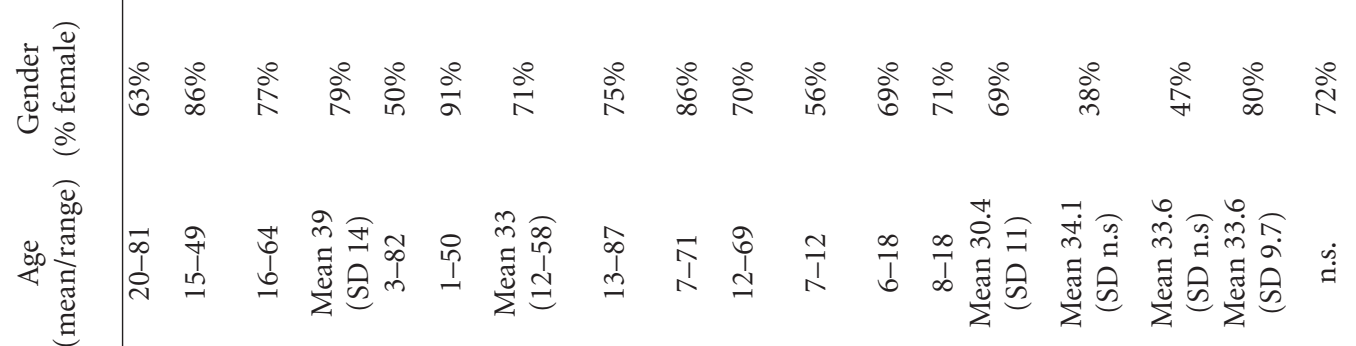
$=\ddot{2}$

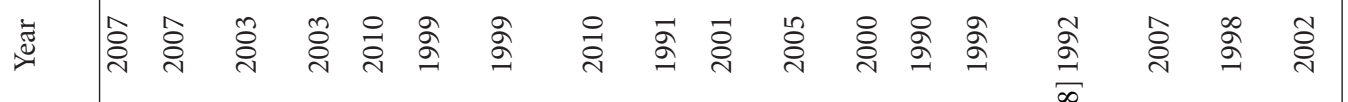

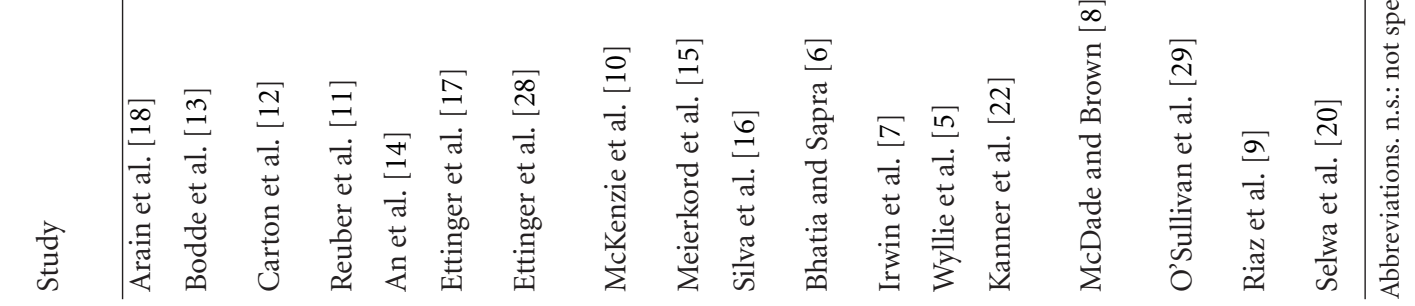


TABLE 2: Factors influencing outcome of patients with psychogenic nonepileptic seizures (PNESs).

\begin{tabular}{|c|c|c|c|c|}
\hline Study & Year & $n$ & Factors associated with "good outcome" & Factors associated with "poor outcome" \\
\hline Reuber et al. [11] & 2007 & 48 & $\begin{array}{l}\text { Better education, motionless spells, shorter } \\
\text { history of condition, attending clinic } \\
\text { accompanied }\end{array}$ & \\
\hline $\begin{array}{l}\text { Sigurdardottir and } \\
\text { Olafsson [3] }\end{array}$ & 2007 & 22 & None statistically significant & $\begin{array}{l}\text { Comorbid psychiatric disorders, negativism } \\
\text { (passive avoidant behaviour, dissatisfaction with } \\
\text { daily life) }\end{array}$ \\
\hline Carton et al. [12] & 2003 & 84 & Relief reaction to diagnosis, employment & $\begin{array}{l}\text { Lack of acceptance/understanding of diagnosis, } \\
\text { continuation of AEDs therapy }\end{array}$ \\
\hline An et al. [14] & 2010 & 64 & Young age at onset & None statistically significant \\
\hline Ettinger et al. [17] & 1999 & 43 & $\begin{array}{l}\text { Good social support, good relationships with } \\
\text { peers as a child }\end{array}$ & Pending litigation \\
\hline Ettinger et al. [28] & 1999 & 76 & Accepting the diagnosis & None statistically significant \\
\hline Irwin et al. [7] & 2000 & 35 & None statistically significant & Comorbid epilepsy \\
\hline Kanner et al. [22] & 1999 & 45 & Single major depressive episode & $\begin{array}{l}\text { Recurrent episodes of depression, personality } \\
\text { disorder, dissociative symptoms, chronic abuse } \\
\text { (physical/emotional/sexual) }\end{array}$ \\
\hline McDade and Brown [8] & 1992 & 16 & None statistically significant & IQ $<80$, past history of violent behaviour \\
\hline McKenzie et al. [10] & 2010 & 260 & $\begin{array}{l}\text { Bullying as the antecedent, male gender, learning } \\
\text { disability }\end{array}$ & $\begin{array}{l}\text { Depression/anxiety, social security payments, } \\
\text { women, PNES only medically unexplained } \\
\text { symptom }\end{array}$ \\
\hline Meierkord et al. [15] & 1991 & 70 & $\begin{array}{l}\text { Female gender, independent lifestyle, absence of } \\
\text { comorbid epilepsy }\end{array}$ & Male gender, coexisting epilepsy \\
\hline Reuber et al. [11] & 2003 & 164 & $\begin{array}{l}\text { Low scores on self-report measures of } \\
\text { inhibitedness, compulsivity, somatization, } \\
\text { depersonalization }\end{array}$ & $\begin{array}{l}\text { Co-morbid epilepsy, poorer education, loss of } \\
\text { consciousness, motor features, older age at } \\
\text { onset/diagnosis }\end{array}$ \\
\hline Selwa et al. [20] & 2002 & 85 & Catatonic type, shorter duration of condition & Thrashing type \\
\hline Silva et al. [16] & 2001 & 17 & Acceptance of diagnosis, independent lifestyle & None statistically significant \\
\hline Wyllie et al. [5] & 1990 & 21 & None statistically significant & None statistically significant \\
\hline
\end{tabular}

friends currently and good relationships as a child were both found to be predictive of a good outcome by Ettinger et al. [17] and the patients who attended clinics unaccompanied had lower seizure remission rates in the study by Arain et al. [18].

Finally, poor education was a predictor of negative outcome in two studies. The study by Reuber et al. [11] found an association with poor global outcome $(P<.05)$, although seizure persistence and dependence showed a nonsignificant relationship. Arain et al. [18] showed increased seizure remission with higher education status.

3.2.4. Diagnostic Latency. Diagnostic latency is an important prognostic variable as it has the potential to be changed by the clinician. One study found a weak association between better outcome and shorter latency between onset and diagnosis [18], only significant when using univariate analysis. The studies by Reuber et al. [11] and Meierkord et al. [15] had longer followup (4 years and 1-14 years compared to 3 months) and a larger sample size, but found no evidence that diagnostic latency is a predictive factor for outcome in PNES.

3.2.5. Reactions to Diagnosis. This area looks at whether acceptance of the diagnosis of PNES has any bearing on its prognosis. Intuitively it may be expected that patients who do not accept their diagnosis have a poorer outcome. This indeed appears to be the case as stated by Carton et al. [12] in their study specifically looking at reactions to diagnosis. According to the findings of this study, the patients who showed relief that their diagnosis was not epilepsy had improved seizure frequency, whereas those who reacted with anger or confusion had a poorer outcome. Interestingly, understanding of the diagnosis of PNES appears to have no bearing on the outcome. Two other studies considered reactions to diagnosis, both finding that acceptance and belief in the diagnosis aided recovery $[16,19]$.

3.2.6. Clinical Features. Several studies found that certain clinical features of PNES can predict outcome. Selwa et al. [20] looked specifically at how the type of seizure affects the outcome of PNES. They found that of the two most common types of seizure ("thrashing" and "catatonic"), patients with catatonic seizures were more likely to have a better prognosis than those with thrashing seizures. In this study, 53\% of "catatonics" were free of seizures compared to $21 \%$ of "thrashers".

These authors defined catatonic seizures as "long periods of motionless unresponsiveness"; in a sample of 48 patients, Arain et al. [18] also found that "motionless" seizures were 
associated with a better outcome. Further support to this hypothesis comes from the study by Reuber et al. [11], in which positive motor features were associated with both a higher level of dependence and persistence of seizures. In addition, loss of consciousness, incontinence, and tongue biting in seizures were linked with markers of poor outcome.

\subsubsection{Psychiatric Comorbidity. Psychopathology in PNES is} well investigated, with patients showing a significantly higher level of psychiatric disorders than the general population. Bodde et al. [13] stated that patients with high psychopathology/negativism scores on the MMPI [21] are less likely to achieve seizure control. In this study, psychopathology included delusional feelings, paranoia and bizarre experiences, whereas negativism consisted of avoidant, aggressive behaviour. No predictive value was found in somatization, shyness, extraversion, or coping strategy. A low somatization score was found to be associated with better prognosis in 164 patients by Reuber et al. [11].

Depression and anxiety have a negative effect on prognosis, with McKenzie et al. [10] reporting that freedom from depression predicts a positive outcome $(\mathrm{OR}=0.43 ; P=$ .012). However, the picture appears more complex in a study of 45 patients by Kanner et al. [22], stating that a single major depressive episode at the onset of PNES results in a good prognosis, whereas recurrent depression is associated with a poor outcome.

The most comprehensive study to analyse the effect of personality on PNES prognosis was the one by Reuber et al. [11], which described a number of personality traits influencing outcome. A standardised questionnaire (DAPP-BQ) was used to assess four aspects of personality pathology, and it was shown that lower scores in emotional dysregulation, inhibitedness, and compulsivity resulted in a better outcome in terms of seizure reduction and reduced dependence at followup. Kanner et al. [22] also showed that a history of personality disorder was associated with persistent recurrence of seizures.

3.2.8. Epilepsy. Three studies found that coexisting epilepsy in patients with PNES is a poor prognostic factor. Meierkord et al. [15] and Irwin et al. [7] agreed that concurrent epilepsy predicted persisting seizures. The study by Reuber et al. [11], however, found no significant association with seizure persistence, but did find that coexisting epilepsy was a strong predictor of persistence of dependent status at followup.

\section{Discussion}

This paper systematically reviewed the available data on the prognosis of PNES, and the factors which influence the outcome of this condition.

It is evident that the prognosis of PNES in adults is poor. From the reviewed data, fewer than 4 in 10 newly diagnosed adults can be expected to become seizure-free within 5 years after diagnosis. In children the figure of patients achieving seizure remission appears to be around $70 \%$, which indicates a more favourable result.
Our results highlight that the prognosis of PNES is overall worse than that of epilepsy (around $60-80 \%$ remission) [19]. These findings should trigger research efforts in the study of PNES treatment using controlled trials. For example, a recent Cochrane review on behavioural interventions in PNES found that only three studies met inclusion criteria for meta-analysis [23]. The lack of methodologically sound research into treatment for a disease with such a poor outcome clearly needs addressing.

The hypothesis that latency from onset to diagnosis of PNES affects prognosis has received little support from studies included in this paper. This is disappointing as time of diagnosis is a variable which could be improved by increasing awareness of PNES among patients and clinicians. More conclusive appears to be the effect of seizure type, with motor seizures having a worse prognosis than the "catatonic" type.

This review also reveals the behavioural profile of a patient with a poor prognosis from PNES: recurrent depression, negativism, somatisation, and dissociative tendencies are all predictors of poor prognosis. This should be taken into account by any intervention programme, as patients with these characteristics are likely to be more difficult to treat.

Coexisting epilepsy as a negative predictive factor has been considered contentious by a previous review [24], however we identified three studies showing that it is associated with persistence of seizures.

In summary, older patients with coexisting epilepsy and suffering from more dramatic seizures tend to have a poorer global outcome. The concomitant presence of somatisation, dissociative disorders, and chronic depression are also predictors of poor prognosis. It appears that patients with chronic PNES struggle to make and maintain relationships, and when told of their diagnosis may react angrily or not accept it altogether. Not infrequently there may be an element of secondary gain.

The most popular way of determining outcome in the reviewed studies was by measuring seizure frequency. This outcome measure is easy to quantify and can easily be compared before- and after-diagnosis or during followup. However, the definition of remission of PNES differs greatly between studies, varying from two weeks to one year of seizure freedom. This makes the results more difficult to compare.

Some criticism has been laid at using solely seizure frequency to measure outcome in PNES. For example, Reuber and colleagues [25] found that $43 \%$ of patients with seizure remission were still unproductive due to other psychiatric disorders. While $60 \%$ of those who still had seizures were also unproductive, the difference was not significant. Further evidence that seizure frequency should not be the sole measure of outcome is derived from a study by Lawton et al. [26]. This study showed that there is no significant correlation between seizure frequency and health-related quality of life when other factors were controlled for. These findings should be carefully considered while interpreting prognosis measured in the reviewed studies, and future research should focus on using a wider variety of outcome measurements, including socioeconomic status, overall level of functioning, and other quality of life indicators. 
The findings of this review should be held in context, considering that only two of the studies included over 100 patients. Other limitations of the review include the fact that most studies were retrospective (and therefore prone to a range of bias problems associated with this study design), that the proportion of patients with known outcomes was always much lower than 100\% (introducing selection bias), and that the definition of a seizure-free outcome differed between the studies reviewed. In many of the studies there are also issues with how particular features (which were then related to outcome) were assessed: for instance, a diagnosis of comorbid epilepsy was defined in different ways, the presence or absence of psychiatric comorbidity was assessed using more or less suitable means. A further limitation of the reviewed literature was the short followup period, suggesting that any conclusions about longer-term outcome should be held with scepticism.

In conclusion, prognosis is poor in adults with PNES, with around $40 \%$ achieving seizure remission, whereas in children the picture is better. Overall, the reviewed studies are consistent with a bimodal outcome distribution, suggesting that PNESs are a heterogeneous condition. The study by McKenzie et al. shows that over a third of patients can stop having seizures if the diagnosis is communicated well. Another prospective multicentre study describes the same phenomenon in one sixth of all patients first seen by an expert and diagnosed [27]. Further research is required on larger samples in order to clarify the impact of sociodemographic and clinical factors on the prognosis of PNES, and to determine their importance relative to each other. Finally, future studies should look at outcome variables other than seizure frequency as it has been shown that social and economic measures can have a larger impact on patients' lives.

\section{References}

[1] A. M. Bloch, Y. Bloch, and U. Kramer, "Psychogenic seizures: a review," International Journal of Adolescent Medicine and Health, vol. 12, no. 1, pp. S71-S85, 2000.

[2] O. Gudmundsson, M. Prendergast, D. Foreman, and S. Cowley, "Outcome of pseudoseizures in children and adolescents: a 6-year symptom survival analysis," Developmental Medicine and Child Neurology, vol. 43, no. 8, pp. 547-551, 2001.

[3] K. R. Sigurdardottir and E. Olafsson, "Incidence of psychogenic seizures in adults: a population-based study in Iceland," Epilepsia, vol. 39, no. 7, pp. 749-752, 1998.

[4] R. P. Lesser, "Psychogenic seizures," Neurology, vol. 46, no. 6, pp. 1499-1507, 1996.

[5] E. Wyllie, D. Friedman, A. D. Rothner et al., "Psychogenic seizures in children and adolescents: outcome after diagnosis by ictal video and electroencephalographic recording," Pediatrics, vol. 85, no. 4, pp. 480-484, 1990.

[6] M. S. Bhatia and S. Sapra, "Pseudoseizures in children: a profile of 50 cases," Clinical Pediatrics, vol. 44, no. 7, pp. 617621, 2005.

[7] K. Irwin, M. Edwards, and R. Robinson, "Psychogenic nonepileptic seizures: management and prognosis," Archives of Disease in Childhood, vol. 82, no. 6, pp. 474-478, 2000.
[8] G. McDade and S. W. Brown, "Non-epileptic seizures: management and predictive factors of outcome," Seizure, vol. 1, no. 1, pp. 7-10, 1992.

[9] H. Riaz, S. Comish, L. Lawton, and B. Scheepers, "Nonepileptic attack disorder and clinical outcome: a pilot study," Seizure, vol. 7, no. 5, pp. 365-368, 1998.

[10] P. McKenzie, M. Oto, A. Russell, A. Pelosi, and R. Duncan, "Early outcomes and predictors in 260 patients with psychogenic nonepileptic attacks," Neurology, vol. 74, no. 1, pp. 64-69, 2010.

[11] M. Reuber, R. Pukrop, J. Bauer, C. Helmstaedter, N. Tessendorf, and C. E. Elger, "Outcome in psychogenic nonepileptic seizures: 1 to 10 -year follow-up in 164 patients," Annals of Neurology, vol. 53, no. 3, pp. 305-311, 2003.

[12] S. Carton, P. J. Thompson, and J. S. Duncan, "Non-epileptic seizures: patients' understanding and reaction to the diagnosis and impact on outcome," Seizure, vol. 12, no. 5, pp. 287-294, 2003.

[13] N. M. G. Bodde, A. M. A. J. Janssen, C. Theuns, J. F. G. Vanhoutvin, P. A. J. M. Boon, and A. P. Aldenkamp, "Factors involved in the long-term prognosis of psychogenic nonepileptic seizures," Journal of Psychosomatic Research, vol. 62, no. 5, pp. 545-551, 2007.

[14] D. M. An, X. T. Wu, BO. Yan, J. Mu, and D. Zhou, "Clinical features of psychogenic nonepileptic seizures: a study of 64 cases in southwest China," Epilepsy and Behavior, vol. 17, no. 3, pp. 408-411, 2010.

[15] H. Meierkord, B. Will, D. Fish, and S. Shorvon, "The clinical features and prognosis of pseudoseizures diagnosed using video-EEG telemetry," Neurology, vol. 41, no. 10, pp. 16431646, 1991.

[16] W. Silva, B. Giagante, R. Saizar et al., "Clinical features and prognosis of nonepileptic seizures in a developing country," Epilepsia, vol. 42, no. 3, pp. 398-401, 2001.

[17] A. B. Ettinger, A. Dhoon, D. M. Weisbrot, and O. Devinsky, "Predictive factors for outcome of nonepileptic seizures after diagnosis," Journal of Neuropsychiatry and Clinical Neurosciences, vol. 11, no. 4, pp. 458-463, 1999.

[18] A. M. Arain, A. M. Hamadani, S. Islam, and B. W. AbouKhalil, "Predictors of early seizure remission after diagnosis of psychogenic nonepileptic seizures," Epilepsy and Behavior, vol. 11, no. 3, pp. 409-412, 2007.

[19] S. Shorvon and A. L. Luciano, "Prognosis of chronic and newly diagnosed epilepsy: revisiting temporal aspects," Current Opinion in Neurology, vol. 20, no. 2, pp. 208-212, 2007.

[20] L. M. Selwa, J. Geyer, N. Nikakhtar, M. B. Brown, L. A. Schuh, and I. Drury, "Nonepileptic seizure outcome varies by type of spell and duration of illness," Epilepsia, vol. 41, no. 10, pp. 1330-1334, 2000.

[21] E. H. M. Eurelings-Bontekoe, I. J. Duijsens, W. M. Snellen, R. W. Diekstra, and G. Ouwersloot, "DSM-III-R and ICD-10 personality disorders and personality dimensions as assessed by the Dutch short form of the MMPI: preliminary results," Personality and Individual Differences, vol. 18, no. 2, pp. 231239, 1995.

[22] A. M. Kanner, J. Parra, M. Frey, G. Stebbins, S. PierreLouis, and J. Iriarte, "Psychiatric and neurologic predictors of psychogenic pseudoseizure outcome," Neurology, vol. 53, no. 5, pp. 933-938, 1999.

[23] J. Martlew, G. A. Baker, L. Goodfellow, N. Bodde, and A. Aldenkamp, "Behavioural treatments for non-epileptic attack disorder," Cochrane Database of Systematic Reviews, no. 4, Article ID CD006370, 2009. 
[24] N. M. G. Bodde, J. L. Brooks, G. A. Baker et al., "Psychogenic non-epileptic seizures-definition, etiology, treatment and prognostic issues: a critical review," Seizure, vol. 18, no. 8, pp. 543-553, 2009.

[25] M. Reuber, A. J. Mitchell, S. Howlett, and C. E. Elger, "Measuring outcome in psychogenic nonepileptic seizures: how relevant is seizure remission?" Epilepsia, vol. 46, no. 11, pp. 1788-1795, 2005.

[26] G. Lawton, R. J. Mayor, S. Howlett, and M. Reuber, "Psychogenic nonepileptic seizures and health-related quality of life: the relationship with psychological distress and other physical symptoms," Epilepsy and Behavior, vol. 14, no. 1, pp. 167-171, 2009.

[27] L. Hall-Patch, R. Brown, A. House et al., "Acceptability and effectiveness of a strategy for the communication of the diagnosis of psychogenic nonepileptic seizures," Epilepsia, vol. 51, no. 1, pp. 70-78, 2010.

[28] A. B. Ettinger, O. Devinsky, D. M. Weisbrot, R. K. Ramakrishna, and A. Goyal, "A comprehensive profile of clinical, psychiatric, and psychosocial characteristics of patients with psychogenic nonepileptic seizures," Epilepsia, vol. 40, no. 9, pp. 1292-1298, 1999.

[29] S. S. O'Sullivan, J. E. Spillane, E. M. McMahon et al., "Clinical characteristics and outcome of patients diagnosed with psychogenic nonepileptic seizures: a 5-year review," Epilepsy and Behavior, vol. 11, no. 1, pp. 77-84, 2007. 


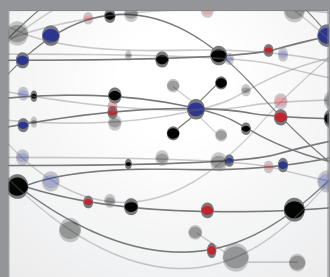

The Scientific World Journal
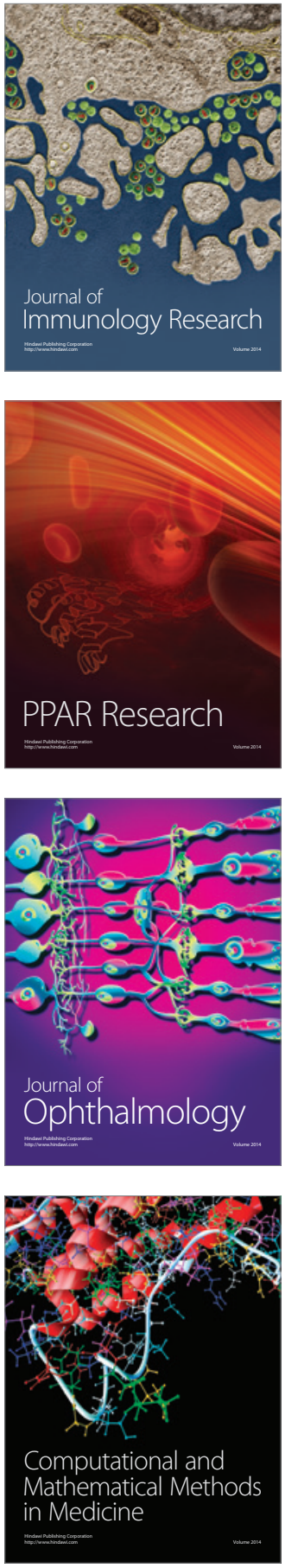

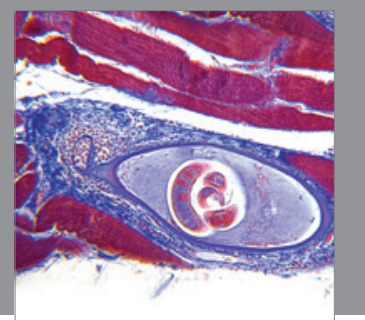

Gastroenterology

Research and Practice
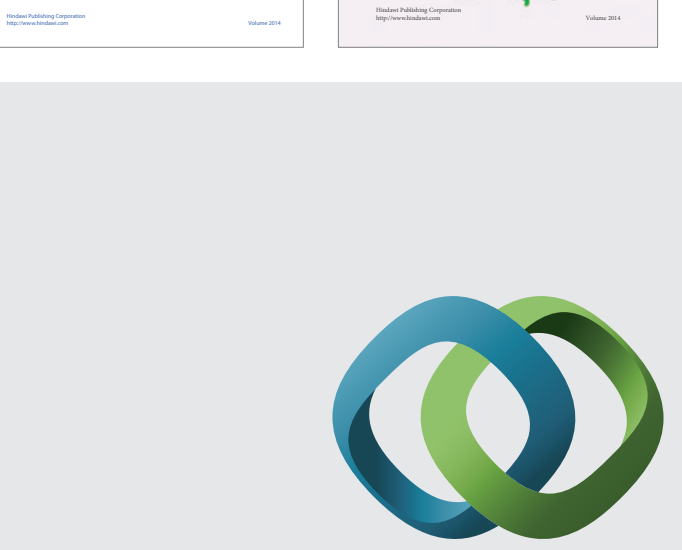

\section{Hindawi}

Submit your manuscripts at

http://www.hindawi.com
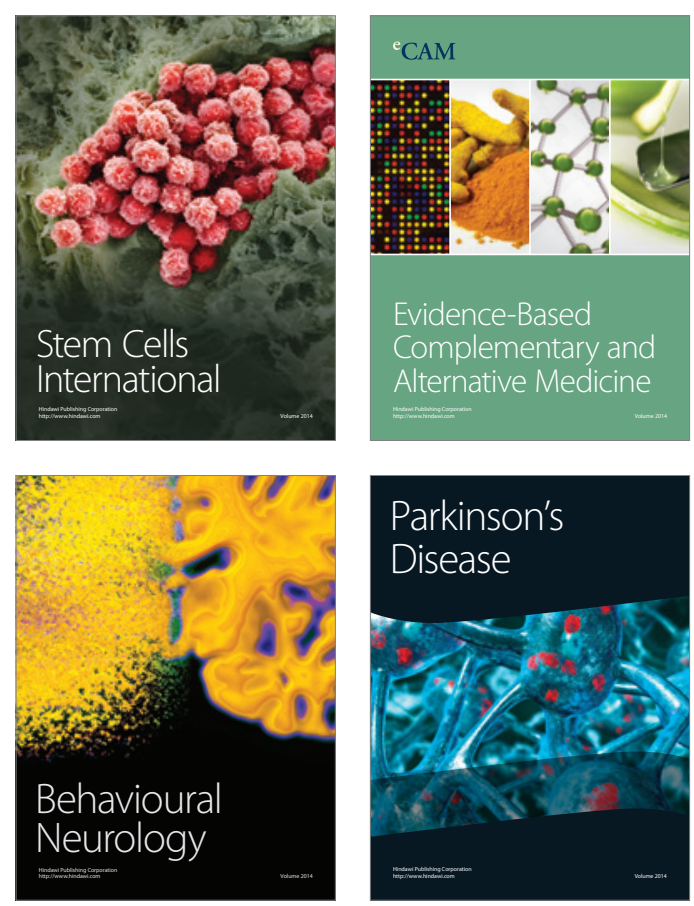

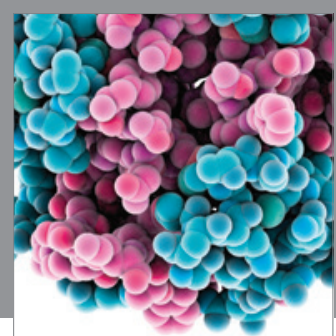

Journal of
Diabetes Research

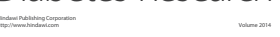

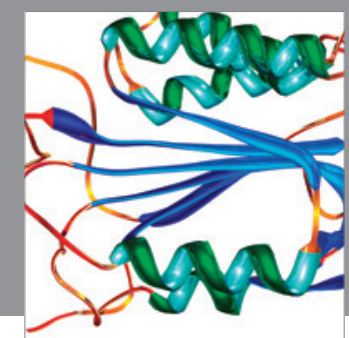

Disease Markers
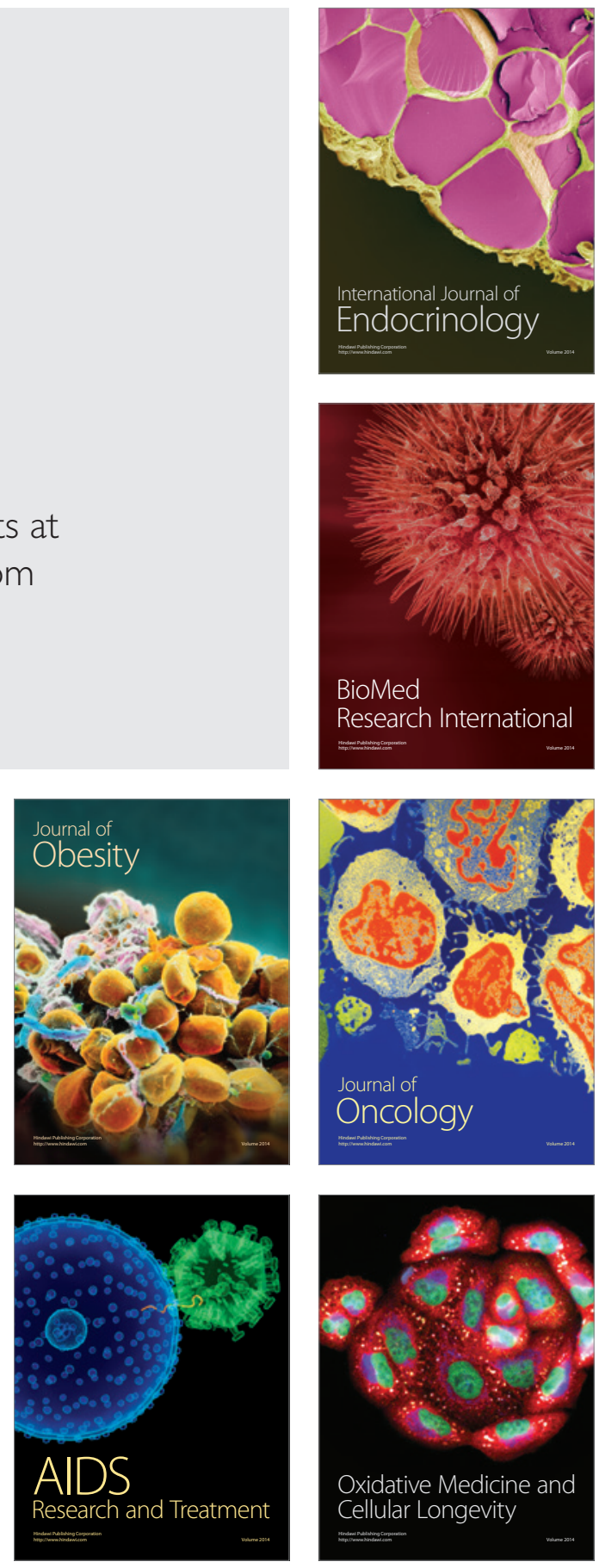